\title{
Study on the Wind-induced Dynamic Response of Wind Power Tower in Consideration of Fluid-structure Interaction Bo SONG ${ }^{1,2, *}$, Yi JIANG ${ }^{1,2, a}$, Shuai HUANG ${ }^{1,2}$, Wen-Shan HE ${ }^{1}$ \\ ${ }^{1}$ University of Science and Technology Beijing, Beijing, 100083, China \\ ${ }^{2}$ Beijing international cooperation base for science and technology, Aseismic research of the rail transit engineering in the strong motion area, Beijing, 100083, China \\ ajiangyi420703739@126.com \\ ${ }^{*}$ Corresponding author
}

Keywords: Wind Power Tower, Fluid-structure Interaction, Elaborate Model, On-site Monitoring, Dynamic Response.

\begin{abstract}
Based on Adina finite element software, this paper established elaborate model in consideration of the fluid-structure interaction between structure and air, then compared the stress between on-site monitoring and the simulation which the wind speed is $5 \mathrm{~m} / \mathrm{s}$. Finally, based on the Davenport wind speed spectrum, this paper analyzed the dynamic response of wind power tower for pulsating wind for $10 \mathrm{a}, 20 \mathrm{a}$ and $50 \mathrm{a}$, and suggested more accurate fluid-structure interaction method when analyzed the wind-induced dynamic response. The study shows: The elaborate simulation method used in this paper is mostly consistent with the on-site monitoring; The FSI method makes a better accuracy than the standardized calculation method; Normal performance of wind power tower structure is determined by the displacement.
\end{abstract}

\section{Introduction}

Wind power tower is a typical top-heavy structure with high height and thin wall, which suffered major load, is wind load, but wind speed and direction constantly changes over time and there are fluid-structure interaction between wind and structure. Therefore, study on wind-induced dynamic response under wind load considering fluid-structure interaction of wind power tower is particularly important.

How to ensure the wind power tower under wind loads without structural failure is an issue which a domestic and foreign scholar is studying. In the finite element simulation, Leishman[1] and Arakwawa[2] using CFD (Computational Fluid Dynamics) studies the flow of wind power tower. Nilay[3] using CFD analyzed the flow field of wind power tower in stall and yaw condition. In limit wind load aspects, Jin Zhihao[4] analyzed the storm wind and lateral wind leaves under the most adverse circumstances. According to Japanese standard, Zeng Jie[5] calculated the wind loads when wind power tower suffered storm, and noted that when the Windmill is stopped, the load suffered by structure under storm is maximum.

While most of the current study of domestic and international don't consider fluid-structure interaction between structure and air, which conducted an impact on correctness of study. In fact, under the action of wind load, wind power tower structure itself will have a certain degree of displacement and deformation of leaves which will also turn, and due to the deformation and displacement, it will have an impact on ambient air, the forms of exercise of the ambient air, causing air and interactions between structures. Therefore, in consideration of fluid-solid interaction effect of wind power tower is more accurate in real project.

Combined actual engineering, using Adina finite element software [6, 7], this paper established wind field model and structure finite element model, compared the simulation results and on-site monitoring results, and validate the correctness of fluid-structure interaction (FSI) method. Finally, analyzed the dynamic response of structure under pulsating wind, cleared the security of structure when leaves is on completely started state and feathering state, then put forward some views, and provide reference for the coming wind vibration response analysis of wind power tower. 


\section{Elaborate Model of Wind Power Tower in Consideration of Fluid-structure Interaction}

\section{Project Background}

The studied research object is a three-bladed wind power tower, whose wheels height is $52.08 \mathrm{~m}$, blade length is $24 \mathrm{~m}$, site belongs to III class site (complex mountain) and it used variable diameter cylinder shaped steel, steel for Q345, it used variable diameter cylinder shaped steel, by 23 section different wall thick Tower tube welding, steel for Q345 steel, site structure figure is shown in Fig.1.

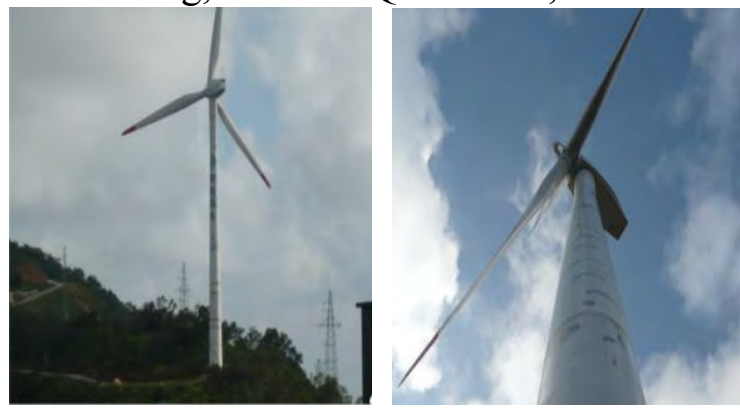

Fig.1 the Site Structure Figure of Wind Power Tower

\section{The Elaborate Model of Wind Power Tower}

By Adina FEM software, fluid-structure interaction model is established, it consists of wind field models and structural models. Air field uses 3-D Fluid elements, whose material density is $1.152 \mathrm{~kg} / \mathrm{m}^{3}$ and can't be compressed. Wind tower shelf use shell63 unit, 3Dsolid units such as blades, wheels, cabin, masses inside of the cabin structure is simplified to focus on the quality of mass considerations, whose material density is $7850 \mathrm{~kg} / \mathrm{m}^{3}$, modulus is $206 \mathrm{MPa}$, consolidation at the bottom, and bi-linear kinematic hardening model recommended by "Design specification of Japan highway bridge (explanation)" [8] from Japan is adopted in the stress-strain relationship of material. Wind field model and structure model of wind power tower is shown in Fig.2.

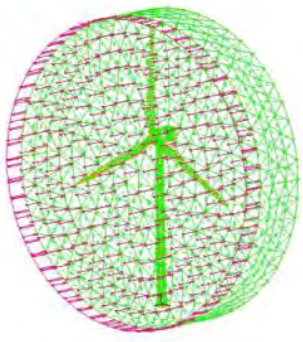

(a)Wind field model

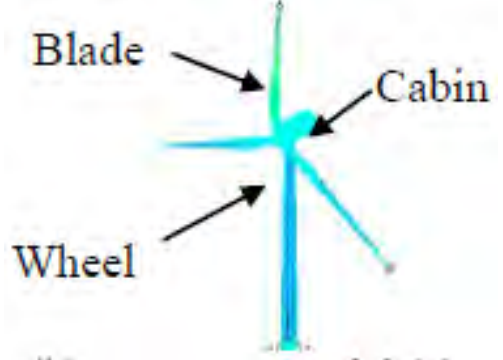

(b)Structure model

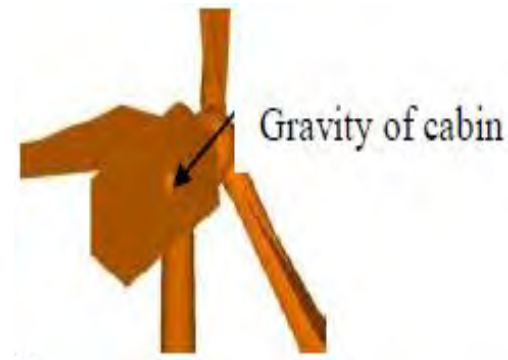

(c)Cabin focus map

Fig. 2 the Model Figure of Wind Power Tower

The dynamic response analysis method of wind power tower under pulsating wind uses time history analysis method.

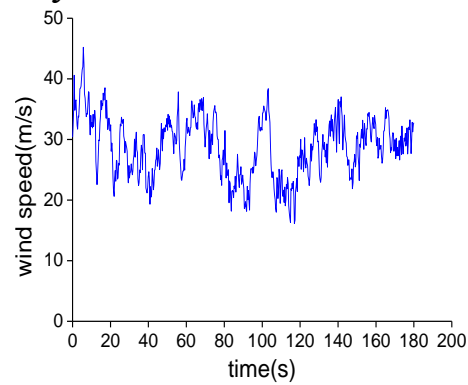

(a) $10 \mathrm{a}$

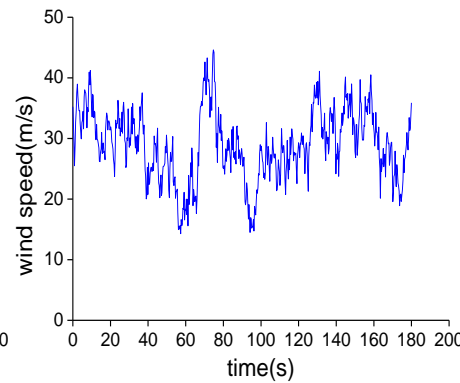

(b) $20 \mathrm{a}$

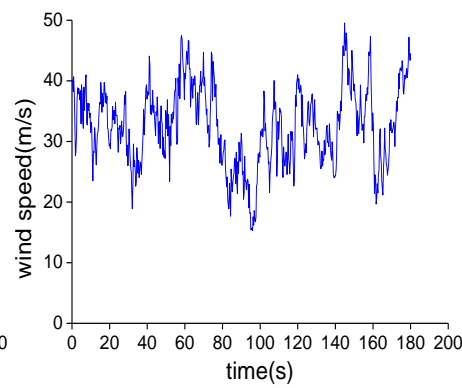

(c) $50 \mathrm{a}$

Fig. 3 the Speed-time Curve under Pulsating Wind 
According to Davenport wind velocity spectrum principle, using Matlab to calculate to get wind speed of wind power tower at hub height for 10a, 20a, 50a. Wind speed time series curve is shown in Fig.3.

\section{On-site Monitoring of Wind Power Tower}

\section{Measured Points of Monitoring}

Wind power tower laid a total of 10 monitoring points; it has external arrangement of 8 points, internal arrangement of 2 points. Structural layout of on-site monitoring points is shown in Fig.4.
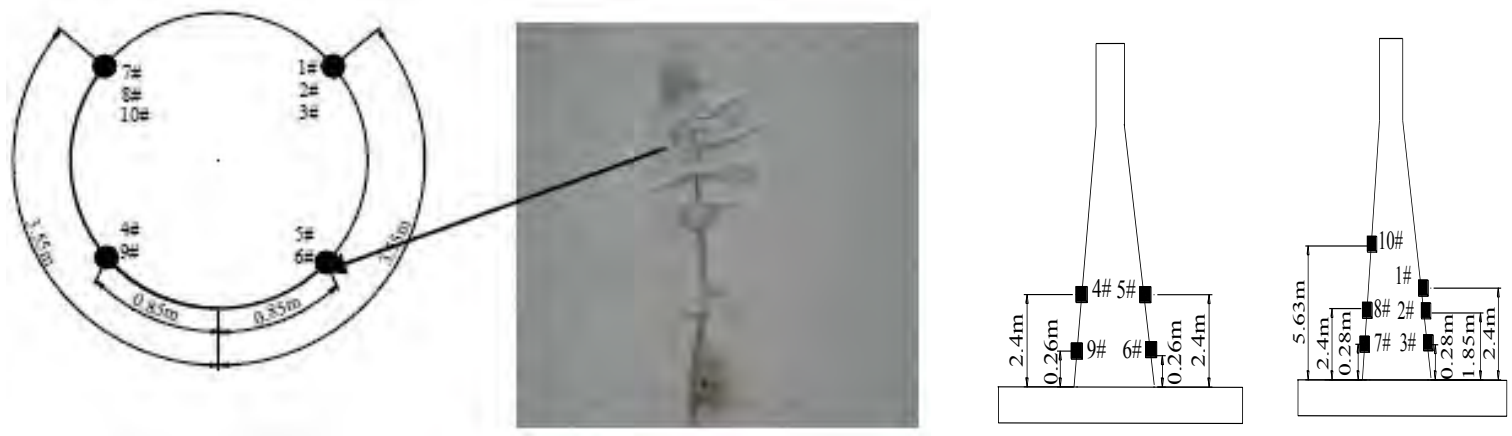

(a)The floor plan of monitor point inside the bottom of wind power tower (b) Each monitoring point distribution along the height of wind power tower

Fig. 4 Measured Points of Monitoring

\section{The Simulation Result of Wind Power Tower under 5m/s Wind Speed}

Studying on the simulation result of wind power tower under $5 \mathrm{~m} / \mathrm{s}$ wind speed for comparison to the monitoring result is shown in Fig.5.
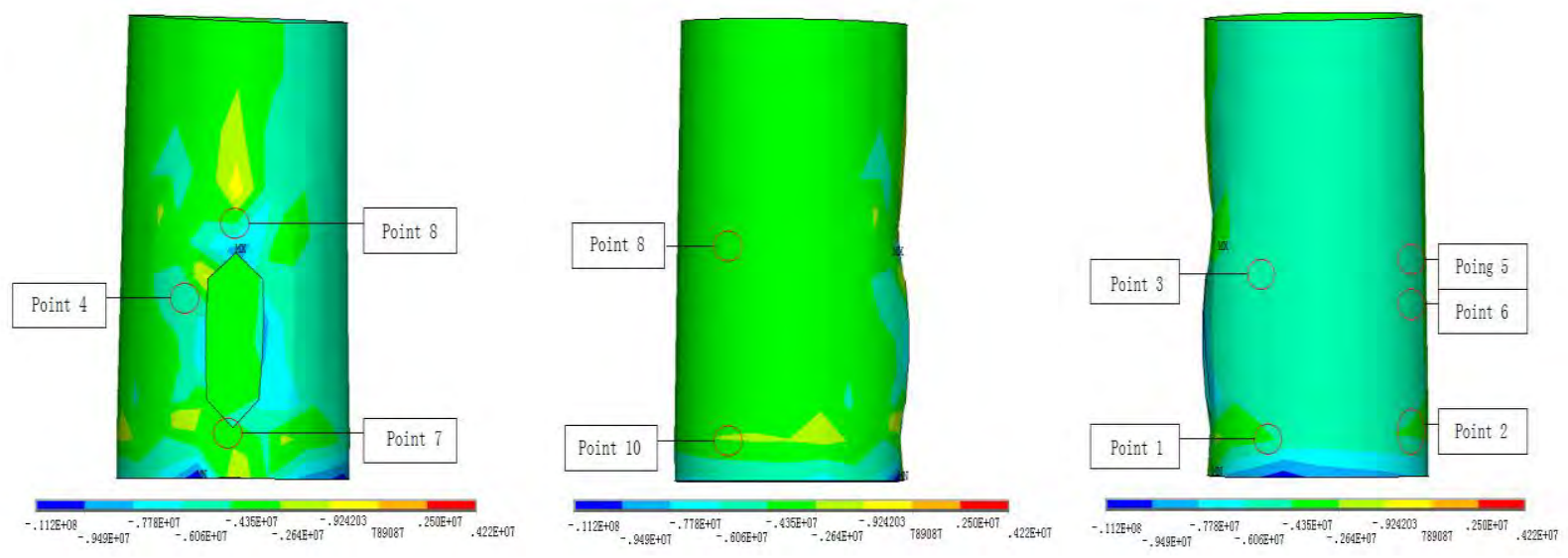

Fig. 5 the Stress of Monitoring Points of Wind Power Tower under $5 \mathrm{~m} / \mathrm{s}$ Wind Speed

\section{Comparison of Results between On-site Monitoring and Analysis of Elaborate Simulation}

Place the anemometer about 10 meters above the ground to test wind speed. According to the measured wind speed conditions, found that the wind speed changes in the $0-6 \mathrm{~m} / \mathrm{s}$, most of time wind speed is $5-6 \mathrm{~m} / \mathrm{s}$. Therefore, the monitor get wind of $0-1 \mathrm{~m} / \mathrm{s}$ strain comparison of monitoring results as initial data, choose the $5-6 \mathrm{~m} / \mathrm{s}$ strain monitoring results. Comparing results between on-site monitoring and analysis of elaborate simulation is shown in table 1.

Table 1 shows that the strain value between monitoring and simulation at the same point have a less difference, and most of the difference was less than $10 \%$, the results are also within the error limits, therefore, the simulation method is feasible. 
Tab. 1 Comparison of Stress Conditions between On-site Monitoring and Analysis of Elaborate Simulation

\begin{tabular}{|cccc|}
\hline $\begin{array}{c}\text { Number of Monitoring } \\
\text { Points }\end{array}$ & $\begin{array}{c}\text { Stress of simulation } \\
\text { (MPa) }\end{array}$ & $\begin{array}{c}\text { Stress of monitoring } \\
(\mathrm{MPa})\end{array}$ & $\begin{array}{c}\text { Percentage of } \\
\text { difference } \\
(\%)\end{array}$ \\
1 & -9.5584 & -8.93422 & $6.99 \%$ \\
2 & -2.8822 & -2.72126 & $5.91 \%$ \\
3 & -8.0902 & -7.6529 & $5.71 \%$ \\
4 & -8.6108 & -8.68084 & $0.81 \%$ \\
5 & -5.3242 & -5.14588 & $3.47 \%$ \\
6 & -0.77456 & -1.22364 & $36.70 \%$ \\
7 & -0.96426 & -1.00322 & $3.88 \%$ \\
8 & -1.55642 & -1.63152 & $4.60 \%$ \\
9 & -9.4966 & -9.45952 & $0.39 \%$ \\
10 & -1.4935 & -1.86842 & $20.07 \%$ \\
\hline
\end{tabular}

\section{Analysis on Dynamic Response of Wind Power Tower under Pulsating Wind}

Due to the effect of ground buildings, air mobility, terrain and other reasons, the wind in the real world is unstable, its size and direction is change over time, space and temperature, especially if wind speed is greater ,the change is obvious. Therefore, it is necessary to study dynamic characteristics of wind power tower under pulsating wind.

The displacement, stress and acceleration response of structure for wind load for 10a, 20a and 50a is shown in Fig.6-Fig.8.

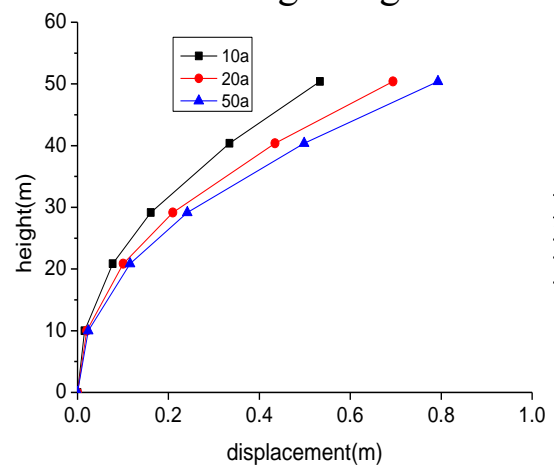

Fig.6 the Maximum Displacement along Height of Tower

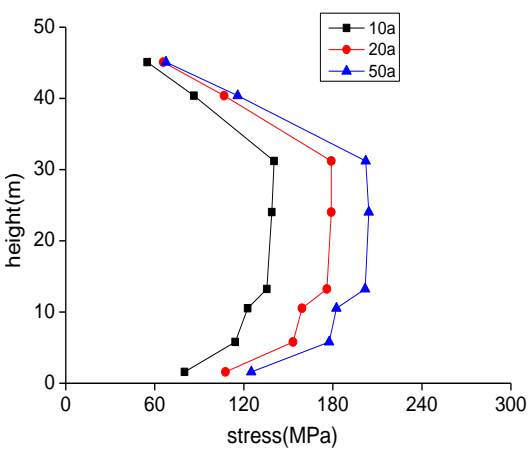

Fig. 7 the Maximum Stress along Height of Tower

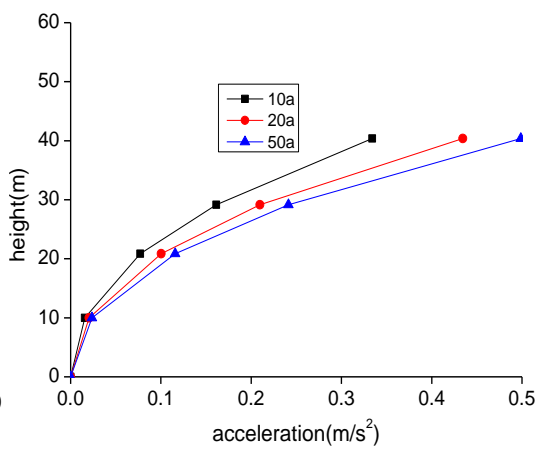

Fig. 8 the Maximum Acceleration along Height of Tower

As shown in Fig.6, the change trend of maximum displacement along height is the same.

The place having maximum displacement is located in the top of tower, it is $0.636 \mathrm{~m}$ under pulsating wind for 10a, and due to China specification "Code for design of high-rising structure" (GB 50135-2006), the limit displacement of tower is $1 / 75$ of the height of structure $(\mathrm{h} / 75=0.6944 \mathrm{~m})$, both are very close. Taking construction defects or other reasons into account, the displacement under pulsating wind for 10a may reach to the limit displacement. Meanwhile, the maximum displacement under pulsating wind for $10 \mathrm{a}$ is compared, the maximum displacement of top of structure increases $0.18 \mathrm{~m}$, for $50 \mathrm{a}$, it increases $0.29 \mathrm{~m}$.

From the foregoing, the central stress of tower reach to maximum under three kinds of pulsating wind, and it did not exceed the minimum allowable stress, but the displacement exceeds the allowable displacement, showing that normal using performance of wind power tower is decided of displacement, furthermore, it should enhance the strength design for central section of tower (for example, increases the thickness of central section of tower).

As shown in Fig.7, the change trend of maximum stress along height is the same. Wind power 
tower bottom bent moments maximum, but stress maximum is occurred in Tower tube Central, and it is 204.6Mpa under pulsating wind for 50 a, which is 1.14 times for 20a and is 1.45 times for 10a, all did not exceed the yield strength (345Mpa) and the allowable stress $(273.01 \mathrm{Mpa})$.

While wind speeds greater, the same wind speed is increased, the smaller the increment of stress and displacement of the structure. This is because wind speed increases, the structure (especially blades) produced large deformation, the shape coefficient and force area changes, it is FSI simulations that takes the change of shape coefficient and force area into account. So relative to the specification method to calculate stress under wind load, the greater wind speeds is, more accurate it is if you use FSI simulation.

As shown in Fig.8, the maximum acceleration of top of tower under pulsating wind for 10a, 20a, $50 \mathrm{a}$ is $0.95 \mathrm{~m} / \mathrm{s}^{2}, 1.51 \mathrm{~m} / \mathrm{s}^{2}$ and $2.3 \mathrm{~m} / \mathrm{s}^{2}$, which made the shear of bottom of tower increase $37.1 \mathrm{kN}$, $59.2 \mathrm{kN}$ and $90.6 \mathrm{kN}$, the bending moment increase $1933.4 \mathrm{kN} \cdot \mathrm{m}, 3083.2 \mathrm{kN} \cdot \mathrm{m}$ and $4718.5 \mathrm{kN} \cdot \mathrm{m}$. So analysis on the dynamic response under wind load should take fluctuating wind effects on structures into account.

\section{Summary}

In consideration on fluid-structure interaction, this paper carried out the wind-induced dynamic response of wind power tower, conclusion is obtained as follows:

(1) Considering fluid-structure interaction, elaborate model is established. Then, by comparison of results between simulation and on-site monitoring, this paper verifies the feasibility of numerical simulation methods. Research shows that the simulation put forward by this paper can provide reference for the design of wind power tower.

(2) Under pulsating wind for 10a, 20a, 50a, the maximum stress, maximum displacement, and maximum acceleration of structure occurred at the same location, and with the increase of same wind speed, The incremental of stress and displacement of structure is smaller, this is because it is FSI simulations that takes the change of shape coefficient and force area into account by comparison with the specification calculation. Therefore, the greater wind speeds is, more accurate it is if you use FSI simulation.it is recommended that it is more accurate using fluid-structure interaction (FSI) method when analyzing the dynamic response of structures under wind load,

(3) Under the pulsating wind, the central stress of tower reach to the maximum, which did not exceed the minimum allowable stress, but exceeds the allowable displacement, indicating that normal performance of wind power tower is determined by the displacement. Furthermore, it should enhance the strength design for central section of tower (for example, increases the thickness of central section of tower).

\section{Acknowledgement}

This paper is supported by Natural Science Foundation of China (51178045) and Overseas Famous Teachers Project of Education Department (MS2011BJKJ005).

\section{References}

[1]Gordon Leishman. Challenges in modeling the unsteady aerodynamics of wind turbines[C]. 21st ASME Wind Energy Symposium and the 40thAIAAAerospace Sciences Meeting, Reno, NV, 2002.

[2]Lida, M, Arakwawa, C. Matsumiya.H. Three dimensional navier-stokes flow field computations through a horizontal axis wind turbine blade[C]. 20th ASME Wind Energy Symposium and the 39th AIAA Aerospace Sciences Meeting, Reno, NV, Jan. 18-11, 2001.

[3]Sezer-Uz01. Nilay, Long, Lyle N. 3-D Time-Accurate CFD Simulations of Wind Turbine Rotor Flow Fields [J]. 44th AIAA Aerospace Sciences Meeting and Exhibit, Reno, NV; USA; 9-12Jan. 2006. PP. 1-23. 2006. 
[4]Jin Zhihao, Fan Xuanhua, Su Xianyue. Research on blade wind-induced vibration in wind direction [J]. 2011 (43), 5:677-681.

[5]Zeng Jie. Study on the influence of FSI effects on the seismic behavior of mono-pile offshore wind power structure [D]. 2014.

[6]Yue G, Chen Q. Fundamental Application and Example Explanation of Adina [M]. Beijing: China Communication Press, 2008.

[7]Yue G, Liang Y B. Advanced User Training of the function of fluid and fluid-structure interaction on Adina [M]. Beijing: China Communication Press, 2010.

[8]Japan Road Association. Design specification of Japan Highway Bridge (explanation) [M], 1996. 